\title{
The Effect of Tartaric Acid-modified Enzyme-resistant Dextrin from Potato Starch on Growth and Metabolism of Intestinal Bacteria
}

\author{
Slizewska Katarzyna1*, Barczynska Renata², Kapusniak Janusz² and Kapusniak Kamila²
}

${ }^{1}$ Institute of Fermentation Technology and Microbiology, Faculty of Biotechnology and Food Sciences, Technical University of Lodz, 171/173 Wolczanska Street, 90-924 Lodz, Poland

2Institute of Chemistry, Environmental Protection and Biotechnology, Jan Dlugosz University, 13/15 Armii Krajowej Avenue, 42-200 Czestochowa, Poland

\begin{abstract}
In present study, enzyme-resistant dextrin, prepared by heating of potato starch in the presence of hydrochloric $(0.1 \% \mathrm{dsb})$ and tartaric $(40 \% \mathrm{dsb})$ acid at $130^{\circ} \mathrm{C}$ for $2 \mathrm{~h}$ (TA-dextrin), was tested as the source of carbon for probiotic lactobacilli and bifidobacteria cultured with intestinal bacteria isolated from faeces of three heathy 70 -year old volunteers. The dynamics of growth of bacterial monocultures in broth containing tartaric acid (TA)-modified dextrin was estimated. It was also investigated whether lactobacilli and bifidobacteria cultured with intestinal bacteria in the presence of resistant dextrin would be able to dominate the intestinal isolates. Prebiotic fermentation of resistant dextrin was analyzed using prebiotic index $(\mathrm{PI})$. Fermentation products were determined by HPLC. It was shown that all of the tested bacteria were able to grow and utilize TA-modified dextrin as a source of carbon, albeit to varying degrees. In co-cultures of intestinal and probiotic bacteria, the environment was found to be dominated by the probiotic strains of Bifidobacterium and Lactobacillus, which is a beneficial effect.
\end{abstract}

Keywords: Resistant dextrin; Prebiotic; Intestinal bacteria

\section{Introduction}

Nowadays, one's lifestyle is indicative of one's future health. Many factors determine the risk of disease, or conversely, the possibility of remaining healthy. Physical activity and an appropriate diet are examples of daily routines that may influence one's health. A lack of physical activity, particularly if associated with overconsumption, increases the risk of development of nutrition-related chronic diseases, such as obesity, hypertension, cardiovascular diseases, osteoporosis, type II diabetes, and several types of cancer. Over the last decade, dramatic changes have taken place in the perception and understanding of the importance of the daily diet. Foods are no longer judged in terms of taste and immediate nutritional needs, but also in terms of their ability to improve the health and well-being of the consumers. The role of diet in human health has led to the recent development of the socalled functional food concept. A functional food is a dietary ingredient that has cellular or physiological effects above its normal nutritional value. It can also contain prebiotics [1].

"A prebiotic is a non-digestible food ingredient that beneficially affects the host by selectively stimulating the growth and/or activity of one or a limited number of bacteria in the colon, and thus improves host health" [2]. The definition updated by Gibson specifies that a prebiotic is "a selectively fermented ingredient that allows specific changes, both in the composition and/or activity in the gastrointestinal microflora that confers benefits upon host well-being and health" [3]. The current definition of prebiotics was suggested during the ISAPP experts' meeting in 2008, according to which "a dietary prebiotic is a selectively fermented ingredient that results in specific changes in the composition and/or activity of the gastrointestinal microbiota, thus conferring benefit(s) upon host health" [4]. For a substance to qualify as a prebiotic, it must meet certain criteria: it must be chemically characterized, exhibit health benefits that are measurable and outweigh any adverse effects, and appropriately modulate the composition or activity of the microbiota in the target host [5].

Some carbohydrates, such as fructo oligosaccharides (FOS) [6,7], inulin [8]; Van Loo, [9], transgalacto-oligosaccharides (TOS)
$[10,11]$ and lactulose [12,13] are well-accepted prebiotics, while isomaltooligosaccharides (IMO) [14] and xylooligosaccharides [15] are candidate prebiotics. The fermentation of some oligosaccharides is not as selective as that of FOS, so their prebiotic status remains in doubt. Promising sources of prebiotics are starch products, especially resistant starch (RS) [16-18], and products of partial degradation of starch, that is, dextrins $[19,20]$.

The objective of this study was to determine whether dextrin obtained as a result of heating starch with tartaric acid (patent claim no. 392894) is a substance with prebiotic properties [7]. Thus, it was examined whether the dextrin would be utilized as a source of carbon by probiotic and intestinal bacteria. It was also investigated whether probiotic lactobacilli and bifidobacteria cultured with intestinal bacteria in the presence of resistant dextrin would be able to dominate the intestinal isolates. In the study, the prebiotic index (PI) and the fermentation products of resistant dextrin were determined.

\section{Materials and Methods}

\section{Materials}

Potato starch and tartaric acid $(\geq 99.5 \%)$ were purchased from Sigma-Aldrich Corp. (Poznan, Poland). Hydrochloric acid and ethanol (96\%) were procured from POCH (Gliwice, Poland). Lactobacillus,

*Corresponding author: Slizewska Katarzyna, Institute of Fermentation Technology and Microbiology, Faculty of Biotechnology and Food Sciences, Technical University of Lodz, 171/173 Wolczanska Street, 90-924 Lodz, Poland Tel: +48 42 6313481; Fax: +48 42 6365976; E-mail: katarzyna.slizewska@p.lodz.pl

Received September 04, 2014; Accepted September 24, 2014; Published September 26, 2014

Citation: Katarzyna S, Renata B, Janusz K, Kamila K (2015) The Effect of Tartaric Acid-modified Enzyme-resistant Dextrin from Potato Starch on Growth and Metabolism of Intestinal Bacteria. J Plant Pathol Microb 6: 269. doi:10.4172/2157 7471.1000269

Copyright: (C) 2015 Katarzyna S, et al. This is an open-access article distributed under the terms of the Creative Commons Attribution License, which permits unrestricted use, distribution, and reproduction in any medium, provided the original author and source are credited. 
Citation: Katarzyna S, Renata B, Janusz K, Kamila K (2015) The Effect of Tartaric Acid-modified Enzyme-resistant Dextrin from Potato Starch on Growth and Metabolism of Intestinal Bacteria. J Plant Pathol Microb 6: 269. doi:10.4172/2157-7471.1000269

Bifidobacterium, Clostridium, Fusobacterium, Escherichia coli and Enterococcus bacteria strains were isolated from feces of three healthy 70 -year old men volunteers. The 24 -h cultures were frozen at $-20^{\circ} \mathrm{C}$ : (a) Lactobacillus, Bifidobacterium bacteria in MRS broth with $20 \%$ glycerol, (b) Fusobacterium, and Clostridium in VL broth, and (c) Escherichia, Enterococcus in a nutrient bouillon with $20 \%$ glycerol. Prior to experiments bacteria were activated by twofold inoculation (3\%) in: (a) liquid MRS broth (Lactobacillus, Bifidobacterium), (b) liquid VL broth (Fusobacterium, Clostridium), and (c) nutrient broth (Escherichia, Enterococcus).

\section{Preparation of dextrin}

Enzyme-resistant tartaric acid-modified dextrin (TA-dextrin) was prepared following the method of Jochym et al. [21]. Thus potato starch was sprayed with hydrochloric acid solution $(0.5 \% \mathrm{w} / \mathrm{w})$ to obtain a final $\mathrm{HCl}$ concentration of $0.1 \%$ on a dry starch basis (dsb). The tartaric acid solution $(20 \% \mathrm{w} / \mathrm{v})$ was then added to obtain a final organic acid concentration of $40 \% \mathrm{dsb}$. Thoroughly mixed sample was dried at $110^{\circ} \mathrm{C}$ to obtain final moisture content below $5 \%$. Dried sample $(10 \mathrm{~g})$ was placed in an anti-pressure bottle (SIMAX), capped and heated at $130^{\circ} \mathrm{C}$ for $2 \mathrm{~h}$ in an ELF $11 / 6$ EUROTHERM CARBOLITE oven (Hope, England). Product was cooled in a desiccator and milled into powder with a particle size of $<1 \mathrm{~mm}$. Dextrin was then washed with $80 \% \mathrm{EtOH}$ to remove excess of tartaric acid, and low molecular weight material formed during dextrinization, dried overnight at $50^{\circ} \mathrm{C}$, and then at $110^{\circ} \mathrm{C}$ for $1 \mathrm{~h}$, and finally milled in a cyclone lab sample mill (UDY Corp., Fort Collins, CO, USA) fitted with a $0.50 \mathrm{~mm}$ screen.

\section{The dynamics of growth of mixtures of bacteria}

The intestinal bacteria Lactobacillus, Bifidobacterium, Escherichia coli, Enterococcus, Clostridium and Fusobacterium were co-cultured in the presence of resistant dextrin to determine whether the beneficial bacteria Lactobacillus and Bifidobacterium can dominate their environment in the presence of a mixture of isolated intestinal bacteria. Inoculants of bacterial monocultures were prepared in such a way that after $24 \mathrm{~h}$ of growth the number of particular bacteria ranged from $3.50 \times 10^{7}$ to $4.50 \times 10^{7} \mathrm{CFU} / \mathrm{mL}$, corresponding to the number of these bacteria in the terminal section of the ileum [22]. The monocultures of bacteria isolated from three 70-year-old persons were incubated in liquid MRS (Lactobacillus and Bifidobacterium), in liquid VL medium (Clostridium and Fusobacterium) and in liquid broth (Escherichia coli and Enterococcus). All monocultures were incubated in sterile $15 \mathrm{~mL}$ test tubes (Marfour) - Lactobacillus, Escherichia coli, Enterococcus under aerobic conditions and Bifidobacterium, Fusobacterium and Clostridium under anaerobic conditions. After incubation, the cultures were centrifuged in a MPW-350R centrifuge (Med. Instruments, Poland) at $9.000 \mathrm{rpm}$ for $10 \mathrm{~min}$ at $22^{\circ} \mathrm{C}$, the supernatant was decanted and the biomass was transferred to $100 \mathrm{~mL}$ of medium of Wynne et al. [23] with the addition of resistant dextrin (TA-dextrin). The cultures were incubated for $168 \mathrm{~h}$ under anaerobic conditions (in similar conditions as in the intestine). Following dilution in physiological salt, the cultures were plated (Koch's plate method) in duplicate immediately after inoculation $(0 \mathrm{~h})$ and after $24,48,72$ and $168 \mathrm{~h}$ on selective media: Lactobacillus on Rogosa agar, Bifidobacterium on RCA agar with the addition of the antibiotic dicloxacillin, Escherichia coli on ENDO agar, Enterococcus on bile-aesculin agar, Clostridium on DRCM agar and Fusobacterium on Schaedler agar with an antibiotic. The plates were incubated for $48 \mathrm{~h}$ at $37^{\circ} \mathrm{C}$; Lactobacillus, Escherichia coli, and Enterococcus under aerobic conditions and Bifidobacterium, Fusobacterium and Clostridium under anaerobic conditions in a Concept 400 anaerobic chamber (Ruskinn Biotrace, USA). The control trial was determined by the trial without the addition of the source carbon.

\section{Determination of prebiotic index (PI)}

Prebiotic fermentation of resistant dextrins were analyzed using quantitative equation (prebiotic index - PI). The PI equation is based on the changes in key bacterial groups during fermentation. The bacterial groups incorporated into this PI equation were bifidobacteria, lactobacilli, clostridia and Fusobacterium. The equation assumes that an increase in the populations of bifidobacteria and/or lactobacilli is a positive effect while an increase in Fusobacterium and clostridia are negative [8].

The PI equation is described below:

$\mathrm{PI}=(\mathrm{Bif} /$ Total $)-($ Fus $/$ Total $)+(\mathrm{Lac} /$ Total $)-(\mathrm{Clos} /$ Total $)$

where PI is prebiotic index; Bif, bifidobacterial numbers at sample time/numbers at inoculation; Fus, Fusobacterium numbers at sample time/numbers at inoculation; Lac, lactobacilli numbers at sample time/ numbers at inoculation; Clos, clostridia numbers at sample time/ numbers at inoculation; Total, total bacteria numbers at sample time/ numbers at inoculation.

\section{pH changes}

Changes in $\mathrm{pH}$ were monitored with an Elmetron $\mathrm{CP}-401 \mathrm{pH}$ meter (Elmetron, Zabrze, Poland).

\section{Determination of fermentation products by High Performance Liquid Chromatography (HPLC)}

Organic acids, aldehydes and ethanol concentrations were determined by HPLC in supernatant liquid. The chromatographic analysis was performed by Finnigan Surveyor HPLC system (Thermo Scientific, Riviera Beach FI., USA) with refractive index (RI Plus) and photodiode (PDA Plus) detectors. The column used was an Aminex HPX 87H, $300 \times 7.8 \mathrm{~mm}$ (HPLC Organic Acid Analysis Column, BioRad, Hercules CA, USA). The mobile phase was $0.005 \mathrm{M} \mathrm{H}_{2} \mathrm{SO}_{4}$. The separation was carried out by isocratic elution with a flow rate of 0.6 $\mathrm{ml} / \mathrm{min}$, and the column temperature was maintained at a constant $60^{\circ} \mathrm{C}$.

Quantification of fermentation products was carried out using the external standard method. Lactic acid, formic acid, acetic acid, propionic acid, butyric acid, succinic acid, ethanol, and acetaldehyde of known retention times were used as external standards. For each standard, solutions were prepared, filtered through $0.22 \mu \mathrm{m}$ syringe filters (Milipore, Belford, USA), and injected into the HPLC system to provide standard curves (concentration versus peak area), and for calculating the quantities of organic acids, aldehydes and ethanol. Linear regression curves based on peak areas were calculated for the individual standards covering a broad range of concentrations (Table $1)$.

\section{Results and Discussion}

It seems likely that prebiotic activity will be exhibited by dextrin obtained by simultaneous thermolysis and chemical modification of potato starch in the presence of a volatile inorganic acid (hydrochloric acid) as a catalyst of the dextrinization process and an excess amount of an organic acid (tartaric acid) as a modifying factor (patent claim no. 392894 "Preparation with prebiotic qualities"). In previous research, Kapusniak et al. [24] analyzed this dextrin in terms of the solubility and $\mathrm{pH}$ of its $1 \%$ aqueous solution, the content of reducing sugars, 
Citation: Katarzyna S, Renata B, Janusz K, Kamila K (2015) The Effect of Tartaric Acid-modified Enzyme-resistant Dextrin from Potato Starch on Growth and Metabolism of Intestinal Bacteria. J Plant Pathol Microb 6: 269. doi:10.4172/2157-7471.1000269

\begin{tabular}{|c|c|c|}
\hline Substance & Calibration regression equation & Retention times (min) \\
\hline Lactic acid & $\mathrm{C}=2.36 \times 10^{-7} \times \mathrm{p}$ & 12.7 \\
\hline Acetic acid & $\mathrm{C}=4.08 \times 10^{-7} \times \mathrm{p}$ & 15.7 \\
\hline Formic acid & $\mathrm{C}=2 \times 10^{-6} \times \mathrm{p}+0.0576$ & 14.4 \\
\hline Propionic acid & $\mathrm{C}=2 \times 10^{-6} \times \mathrm{p}+0.0218$ & 18.5 \\
\hline Butyric acid & $\mathrm{C}=2 \times 10^{-6} \times \mathrm{p}+0.0182$ & 16.7 \\
\hline Succinic acid & $\mathrm{C}=1.97 \times 10^{-7} \times \mathrm{p}$ & 12.2 \\
\hline Acetaldehyde & $\mathrm{C}=4.27 \times 10^{-7} \times \mathrm{p}$ & 17.5 \\
\hline Ethanol & $\mathrm{C}=3.85 \times 10^{-7} \times \mathrm{p}$ & 22.6 \\
\hline
\end{tabular}

C: The concentration of the analyzed substances $(\mathrm{mg} / 100 \mathrm{ml})$. P: Peak area.

Table 1: Regression equation and retention time for HPLC standards.

molecular mass distribution, weight average molecular mass using high performance size-exclusion chromatography (HPSEC), average chain length using high performance anion exchange chromatography with pulsed amperometric detection (HPAEC-PAD), and the content of the resistant fraction using the enzymatic-gravimetric method AOAC 991.43 [25], the enzymatic-gravimetric-chromatographic method AOAC 2001.03 [26], the enzymatic-spectrophotometric method [27], and the pancreatin-gravimetric method [28]. It has been shown that the use of tartaric acid in the process of starch thermolysis yields acidic dextrin characterized by high water solubility (about 68\%) and a high content of reducing sugars (about 29\%). It has also been found that dextrin modified with tartaric acid does not contain any traces of unreacted starch, and the percentage share of the main fraction (having a weight average molecular mass of about $1.800 \mathrm{~g} / \mathrm{mol}$ ) was $80 \%$. The average length of the carbohydrate chain in dextrin obtained with tartaric acid was 8.2 as determined by means of HPAEC. A study by Kapusniak et al. [24] revealed that the content of the resistant fraction in dextrin modified with tartaric acid, determined by means of AOAC 991.43, amounted to $44.5 \%$. However, the results obtained by the Englyst enzymatic-spectrophotometric method showed that the actual content of the resistant fraction was above 68\% [27]. Kapusniak et al. [24] used the official AOAC 2001.03 method to determine the content of the resistant fraction in dextrin modified with tartaric acid. This is the latest approved method for determining the total content of dietary fiber in foods containing resistant maltodextrins. Apart from measuring the content of insoluble dietary fiber and the high molecular weight fractions

\section{Lactobacillus}

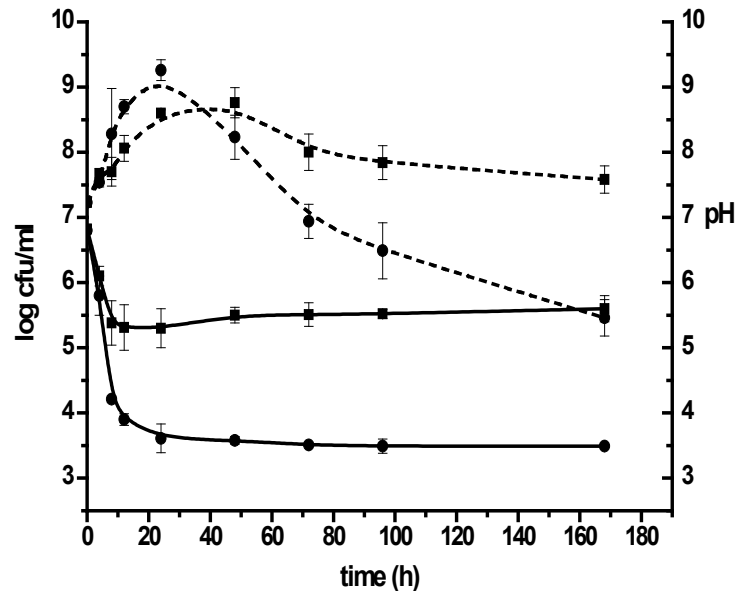

of soluble fiber, this method makes it possible to determine resistant oligosaccharides (by using high-performance liquid chromatography, HPLC). Currently, many authors define resistant starch as the starch fraction that remains undigested by amylolytic enzymes after $16 \mathrm{~h}$. In the Englyst method, fractions undigested after $120 \mathrm{~min}$ are considered resistant. In the pancreatin-gravimetric method, similarly as in the Englyst method, samples are digested with pancreatin, but resistant fractions are determined gravimetrically only after $16 \mathrm{~h}$. In the case of dextrin modified with tartaric acid, the results of determination by the pancreatin-gravimetric method (67\%) were similar to those obtained in previous studies using the Englyst method (68\%), but much higher than those obtained using the AOAC 2001.03 method (50\%) [27,24]. The observed differences among the various methods in terms of the measured content of the resistant fraction in dextrin modified with tartaric acid was caused by the fact that, according to the latest reports, enzymatic-gravimetric methods (including AOAC 2001.03) using thermostable $\alpha$-amylase can determine only part of resistant starch type 4 [29]. And based on enzymatic tests, it can be argued that dextrin obtained using an excessive amount of tartaric acid may be classified as resistant starch type 4 .

In the present study, enzyme-resistant dextrin, prepared by heating of potato starch in the presence of hydrochloric $(0.1 \% \mathrm{dsb})$ and tartaric $(40 \% \mathrm{dsb})$ acid at $130^{\circ} \mathrm{C}$ for $2 \mathrm{~h}$ (TA-dextrin), was tested as the source of carbon for probiotic lactobacilli and bifidobacteria cultured with the intestinal bacteria isolated from the feces of three healthy 70 -year-old volunteers.

In media where TA-dextrin was the source of carbon, all Lactobacillus and Bifidobacterium strains reached the stationary phase at $24 \mathrm{~h}$ of incubation. The number of bacteria of the genus Lactobacillus and Bifidobacterium in the stationary phase was similar and amounted to: $8.70 \log \mathrm{cfu} / \mathrm{mL}$ and $8.41 \mathrm{cfu} / \mathrm{mL}$, respectively. At $168 \mathrm{~h}$ of culture in a medium with dextrin modified with tartaric acid, the number of lactobacilli and bifidobacteria remained high and ranged from 7.75 to $7.91 \log \mathrm{cfu} / \mathrm{mL}$, which shows their substantial viability (Figure 1).

The control strains were cultured in media with glucose. At $24 \mathrm{~h}$ of incubation, in cultures with glucose the number of lactobacilli and bifidobacteria amounted to from 9.35 to $8.83 \log \mathrm{cfu} / \mathrm{mL}$. The bacteria entered the stationary phase, similarly as in media containing dextrin,

\section{Bifidobacterium}

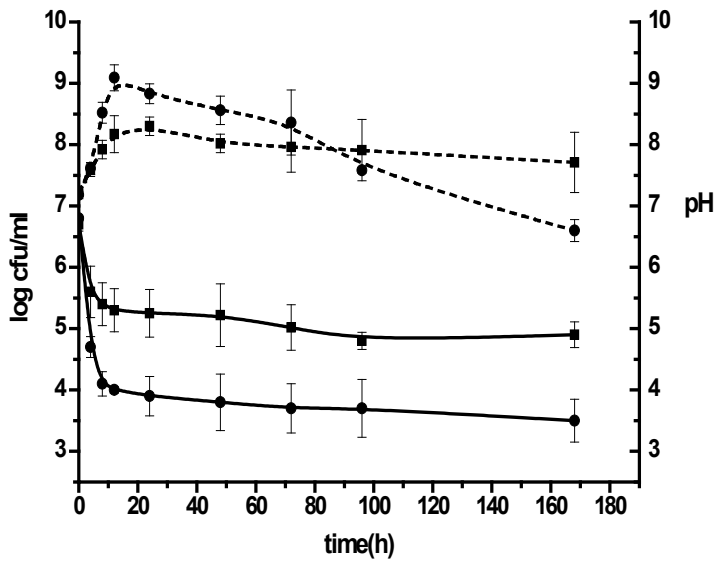

Figure 1: The growth curves (--) and changes in $\mathrm{pH}(-)$ for Lactobacillus and Bifidobacterium bacteria grown in the medium containing TA-dextrin (- ) or glucose (control) $(\bullet)$. Results show means and standard deviations of $n=3$ replicates. 
Citation: Katarzyna S, Renata B, Janusz K, Kamila K (2015) The Effect of Tartaric Acid-modified Enzyme-resistant Dextrin from Potato Starch on Growth and Metabolism of Intestinal Bacteria. J Plant Pathol Microb 6: 269. doi:10.4172/2157-7471.1000269

after $24 \mathrm{~h}$ of incubation. However, the stationary phase lasted much shorter than in media containing dextrin. At $168 \mathrm{~h}$ of culture, the number of viable Lactobacillus and Bifidobacterium cells cultured with glucose was much lower than that of cells cultured with resistant dextrin, and amounted to from 5.56 to $6.70 \log \mathrm{cfu} / \mathrm{mL}$ (Figure 1).

In the medium containing dextrin, the acidifying activity of bifidobacteria was higher than that of lactobacilli. After incubation, a test of culture $\mathrm{pH}$ revealed that Bifidobacterium had the highest acidifying activity ( $\mathrm{pH} 4.9$ ), while Lactobacillus - the lowest ( $\mathrm{pH} 5.6$ ). In the control medium containing glucose, the $\mathrm{pH}$ of Lactobacillus and Bifidobacterium cultures decreased much more than that in the medium containing dextrin; at $168 \mathrm{~h}$ the $\mathrm{pH}$ was 3.50 (Figure 1).

In media containing TA-dextrin, the other bacteria isolated from human feces were able to grow, but the degree of dextrin utilization depended on the strain. In media with resistant dextrin, bacteria entered the stationary phase between 12 and $48 \mathrm{~h}$ of incubation and it lasted for 20-30 consecutive hours. In this phase, the highest cell count was found for Fusobacterium strains ( $8.50 \log \mathrm{cfu} / \mathrm{mL}$ ) (Figure 2). Also Enterococcus strains grew successfully, with the number of cells in the stationary phase reaching $8.49 \log \mathrm{cfu} / \mathrm{mL}$. Lower growth was found for E. coli and Clostridium strains ( 8.31 and $8.26 \log \mathrm{cfu} / \mathrm{mL}$, respectively) (Figure 2). In media containing dextrin, bacteria isolated from human feces preserved high viability, and at $168 \mathrm{~h}$ the number of viable cells was by 1-2.5 log cycles larger than that of the control cells cultured with glucose.

Out of the bacteria isolated from human feces, the most acidifying ones were Clostridium strains, which decreased pH to about 3.50. In cultures containing dextrin, no significant differences were found between the remaining strains, as the $\mathrm{pH}$ ranged from 4.51 to 5.50 . The strains were most active by $24 \mathrm{~h}$ of incubation; later on the $\mathrm{pH}$ values did not change significantly (Figure 2).

It was shown that all the bacteria isolated from human feces were able to grow and utilize TA-dextrin as a source of carbon, albeit to varying degrees. The highest growth was recorded for Lactobacillus and Bifidobacterium. Bifidobacterium strains were also characterized by the highest acidifying activity (lowering $\mathrm{pH}$ to 4.9 ), which remains consistent with the results reported by other authors [15,30,31]. The weakest growth was observed for Clostridium and E. coli. It was found that the stationary phase for Lactobacillus and Bifidobacterium strains was much longer than for other intestinal bacteria. After prolonging culture time to $72-168 \mathrm{~h}$, which corresponds to retarded or pathological passage of digesta through the large intestine, the viability of intestinal bacteria in a medium with resistant dextrin was found to be lower by 1-1.5 log cycles than that of Lactobacillus and Bifidobacterium. The
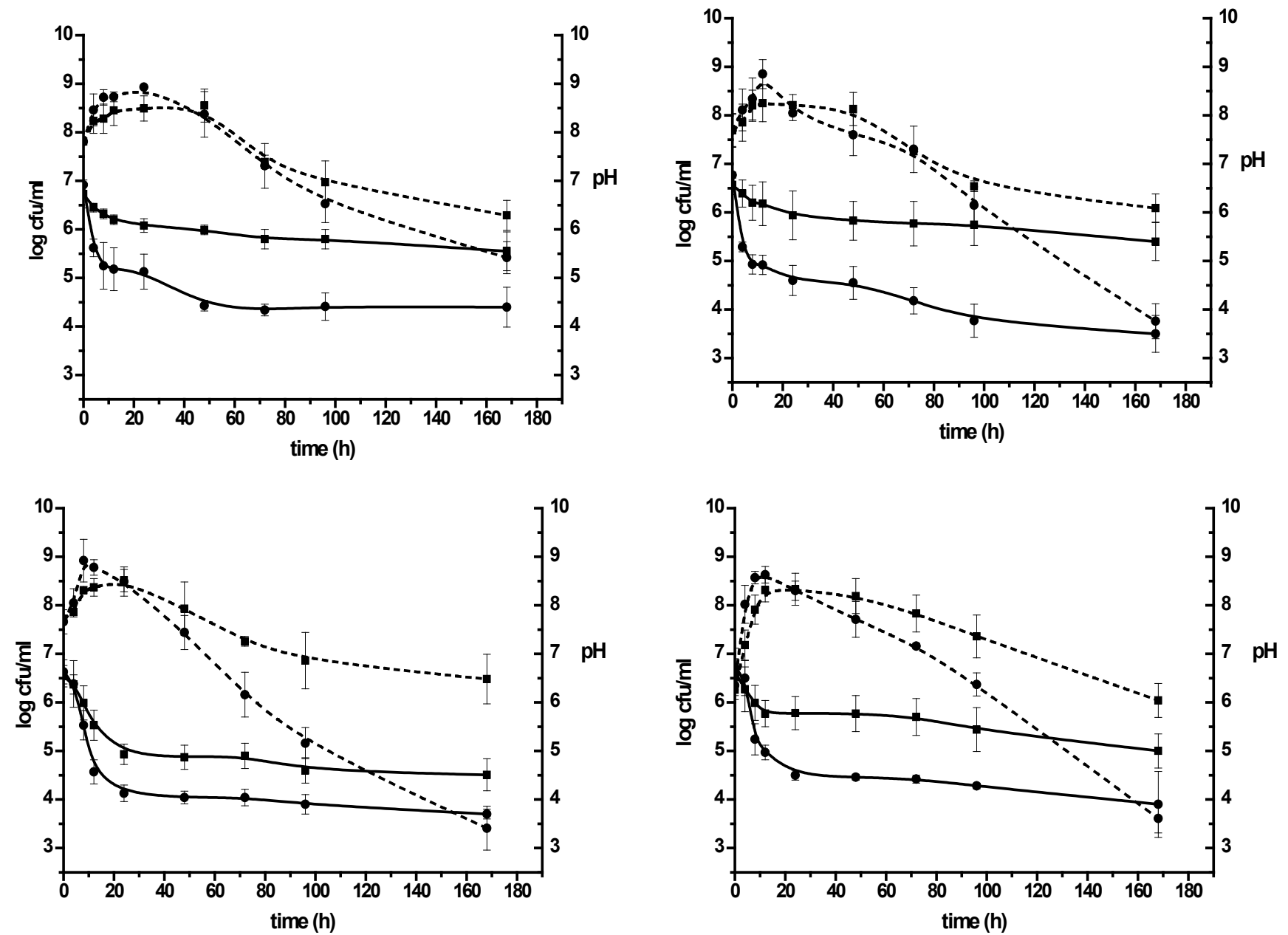

Figure 2: The growth curves (--) and changes in $\mathrm{pH}(-)$ for Fusobacterium, Clostridium, Enterococcus and Escherichia coli bacteria grown in the medium containing TA-dextrin $(\bullet)$ or glucose (control) $(\bullet)$. Results show means and standard deviations of $n=3$ replicates. 
Citation: Katarzyna S, Renata B, Janusz K, Kamila K (2015) The Effect of Tartaric Acid-modified Enzyme-resistant Dextrin from Potato Starch on Growth and Metabolism of Intestinal Bacteria. J Plant Pathol Microb 6: 269. doi:10.4172/2157-7471.1000269

Page 5 of 6

\begin{tabular}{|c|c|c|c|c|c|c|}
\hline $\begin{array}{l}\text { Fermentation } \\
\text { products }\end{array}$ & Lactobacillus & Bifidobacterium & Escherichia coli & Enterococcus & Clostridium & Fusobacterium \\
\hline Lactic acid & $112.7 \pm 0.81$ & $109.5 \pm 0.42$ & $85.0 \pm 1.00$ & $90.2 \pm 1.50$ & $55.2 \pm 0.90$ & $53.5 \pm 0.21$ \\
\hline Acetic acid & $1.5 \pm 0.15$ & $18.2 \pm 0.50$ & $19.5 \pm 0.15$ & $6.5 \pm 0.30$ & $71.5 \pm 0.05$ & $14.0 \pm 0.15$ \\
\hline Formic acid & 0 & $49.2 \pm 0.25$ & $84.5 \pm 0.26$ & $60.0 \pm 0.15$ & 0 & 0 \\
\hline Propionic acid & $4.5 \pm 0.01$ & $4.6 \pm 0.45$ & 0 & 0 & 0 & $390.0 \pm 1.85$ \\
\hline Butyric acid & $20.0 \pm 0.12$ & $11.5 \pm 0.25$ & 0 & 0 & $80.5 \pm 0.51$ & 0 \\
\hline Succinic acid & 0 & 0 & $6.0 \pm 0.10$ & $1.7 \pm 0.10$ & $9.2 \pm 0.11$ & $28.1 \pm 1.00$ \\
\hline Acetaldehyde & $2.2 \pm 0.15$ & $0.3 \pm 0.15$ & $5.5 \pm 0.01$ & $5.0 \pm 0.15$ & $0.3 \pm 0.02$ & $5.1 \pm 0.1$ \\
\hline Ethanol & $0.20 \pm 0.01$ & $0.15 \pm 0.02$ & $0.09 \pm 0.01$ & $0.08 \pm 0.01$ & $0.07 \pm 0.01$ & 0 \\
\hline
\end{tabular}

SD: Standard Deviation; $\mathrm{n}=3$ replicates.

Table 2: Concentration $(\mathrm{mg} / 100 \mathrm{ml})$ of fermentation products after 24-h incubation of bacteria isolated from gastrointestinal tract of man in the broth containing TA-dextrin as the only one source of carbon.

number of Lactobacillus, Bifidobacterium, and other bacteria isolated from fecal samples grown in media containing $1 \%$ glucose was lower by 1-2.5 log cycles than that of corresponding bacteria grown in a medium containing dextrin. This may have been caused by the lower $\mathrm{pH}$ values of the controls, under which the culture environment became unfavorable to preserving high viability by the studied bacteria. This may have also been caused by the protective effects of dextrin on the bacteria.

It was shown that the PI values in media with TA-dextrin were positive; furthermore, the prebiotic index increased with the time of culture (from 0.24 at $24 \mathrm{~h}$ of incubation to 0.31 at $168 \mathrm{~h}$ ), which proves that beneficial bacteria (Bifidobacterium and Lactobacillus) can dominate their environment in the presence of a mixture of intestinal bacteria cultured with the addition of resistant dextrin.

The calculated PI values for TA-dextrin were higher than those reported by Olano-Martin et al. [32] or by Kordyl [33] inulin and oligosaccharides under the same incubation conditions (anaerobiosis; $1 \%$ prebiotic addition; $\mathrm{pH} 6.8$; incubation temperature of $37^{\circ} \mathrm{C}$ ), which shows that TA-dextrin may act as a prebiotic substance.

The HPLC results indicate that the main metabolite produced by Lactobacillus and Bifidobacterium was lactic acid (Table 2). Depending on the bacterial strain, its concentration after $24 \mathrm{~h}$ of incubation ranged from $109.5 \mathrm{mg} / 100 \mathrm{~mL}$ for Bifidobacterium to $112.7 \mathrm{mg} / 100 \mathrm{~mL}$ for Lactobacillus.

Another fermentation product was acetic acid $(1.5 \mathrm{mg} / 100 \mathrm{~mL}$ for Lactobacillus and $18.2 \mathrm{mg} / 100 \mathrm{~mL}$ for Bifidobacterium), propionic acid (4.5-4.6 mg/100 mL for Lactobacillus and Bifidobacterium), and butyric acid $(20.0 \mathrm{mg} / 100 \mathrm{~mL}$ for Lactobacillus and $11.5 \mathrm{mg} / 100 \mathrm{~mL}$ for Bifidobacterium). Bifidobacteria generated up to $50 \mathrm{mg} / 100 \mathrm{~mL}$ of formic acid. Furthermore, Lactobacillus and Bifidobacterium strains fermenting TA-dextrin produced acetaldehyde ( 0.3 to $2.2 \mathrm{mg} / 100 \mathrm{~mL})$ and ethanol (0.1-0.2 mg/100 mL).

It was found that the main metabolite produced during the fermentation of TA-dextrin by Fusobacterium was propionic acid, with a concentration reaching $390 \mathrm{mg} / 100 \mathrm{~mL}$. Fusobacterium also produced lactic acid $(53.5 \mathrm{mg} / 100 \mathrm{~mL})$, succinic acid $(28.1 \mathrm{mg} / 100$ $\mathrm{mL})$, acetic acid $(14.0 \mathrm{mg} / 100 \mathrm{~mL})$, and small amounts of acetaldehyde $(5.1 \mathrm{mg} / 100 \mathrm{~mL})($ Table 1$)$.

The fermentation of TA-dextrin by Enterococcus led mostly to lactic and formic acids. The concentration of those acids, determined by means of HPLC, amounted to 90.2 and $60.0 \mathrm{mg} / 100 \mathrm{~mL}$, respectively [34-36]. The average concentration of acetic acid and acetaldehyde was comparable and ranged from 6.5 to $5.0 \mathrm{mg} / 100 \mathrm{~mL}$. Furthermore, Enterococcus produced traces of ethanol $(0.08 \mathrm{mg} / 100 \mathrm{~mL})$ (Table 2).
According to the results, the major products of the fermentation of TA-dextrin by Clostridium were butyric, acetic and lactic acids. The concentration of these acids was $80.5,71.5$, and $55.2 \mathrm{mg} / 100 \mathrm{~mL}$, respectively. The concentration of other metabolites, namely succinic acid and acetaldehyde, was considerably lower. Moreover, traces of ethanol were also present (Table 1).

The HPLC results showed that E. coli also metabolized TAdextrin, producing a considerable amount of lactic and formic acids, at concentrations reaching $85 \mathrm{mg} / 100 \mathrm{~mL}$. The concentration of another fermentation product, acetic acid, was $19.5 \mathrm{mg} / 100 \mathrm{~mL}$. Succinic acid and acetaldehyde were produced at a similar level $(5.5-6.0 \mathrm{mg} / 100 \mathrm{~mL})$. E. coli produced traces of ethanol as well (Table 2).

\section{Conclusions}

The experiments showed that dextrin obtained as a result of heating potato starch in the presence of hydrochloric acid $(0.1 \%$ of starch dry mass) and tartaric acid ( $40 \%$ of starch dry mass) at $130^{\circ} \mathrm{C}$ for $2 \mathrm{~h}$ may have prebiotic properties. The presented results are promising, but, according to the recommendations of FAO experts concerning the applications of prebiotics, it is still necessary to continue with in vivo experiments, which are now being conducted.

\section{Acknowledgment}

The study was supported by the Polish Ministry of Science and Higher Education, Grant No. N N312 335339

\section{References}

1. Slizewska K, Kapusniak J, Barczynska R, Jochym K (2012) Resistant Dextrins as Prebiotic. In: Chang C-F (edn) Carbohydrates - Comprehensive studies on glycobiology and glycotechnology, In Tech, Rijeka, Croatia, pp. 261-288.

2. Gibson GR, Roberfroid MB (1995) Dietary modulation of the human colonic microbiota: introducing the concept of prebiotics. J Nutr 125: 1401-1412.

3. Gibson GR (2004) Fibre and effects on probiotics (the prebiotic concept). Clin Nutr Suppl 1: 25-31.

4. ISAPP (2008) 6th Meeting of the International Scientific Association of Probiotics and Prebiotics, London, Ontario.

5. FAO (2007) Technical Meeting on Prebiotics. Food Quality and Standards Service (AGNS), Food and Agriculture Organization of the United Nations (FAO). FAO Technical meeting Report, 15-16.

6. Roberfroid M, Gibson GR, Hoyles L, McCartney AL, Rastall R, et al. (2010) Prebiotic effects: metabolic and health benefits. Br J Nutr 104 Suppl 2: S1-63.

7. Slizewska K, Kapusniak J, Barczynska R, Libudzisz Z, Jochym K (2010) Preparation of prebiotic properties, Polish patent claim P-392895.

8. Palframan R, Gibson GR, Rastall RA (2003) Development of a quantitative tool for the comparison of the prebiotic effect of dietary oligosaccharides. Lett App Microbiol 37: 281-284.

9. Van Loo J, Gibson GR (2006) Inulin-type fructans as prebiotics. In: Rastal 
Citation: Katarzyna S, Renata B, Janusz K, Kamila K (2015) The Effect of Tartaric Acid-modified Enzyme-resistant Dextrin from Potato Starch on Growth and Metabolism of Intestinal Bacteria. J Plant Pathol Microb 6: 269. doi:10.4172/2157-7471.1000269

RA (edn) Prebiotics. Development and Application, John Wiley and Sons, Chichester, pp. 57-100.

10. Davis LM, Martínez I, Walter J, Hutkins R (2010) A dose dependent impact of prebiotic galactooligosaccharides on the intestinal microbiota of healthy adults. Int J Food Microbiol 144: 285-292.

11. Sako T, Matsumoto K, Tanaka R (1999) recent progress on research and applications of non-digestible galacto oligosaccharides. Int Dairy J 9: 69-80.

12. Sekhar MS, Unnikrishnan MK, Rodrigues GS, Mukhopadhyay C (2013) Synbiotic formulation of probiotic and lactulose combination for hepatic encephalopathy treatment: a realistic hope? Med Hypotheses 81: 167-168.

13. Tuohy KM, Ziemer CJ, Klinder A, Knobel Y, Pool-Zobel BL et al. (2002) A human volunteer study to determine the prebiotic effects of lactulose powder on human colonic microbiota, Microb Ecol Health Dis 14: 165-173.

14. Kaneko T, Yokoyama A, Suzuki M (1995) Digestibility characteristics of isomaltooligosaccharides in comparison with several saccharides using the rat jejunum loop method. Biosci Biotechnol Biochem 59: 1190-1194.

15. Crittenden RG, Morris LF, Harvey ML, Tran LT, Mitchell HL, et al. (2001) Selection of a Bifidobacterium strain to complement resistant starch in a synbiotic yoghurt. J Appl Microbiol 90: 268-278.

16. Fuentes-Zaragoza E, Sanchez-Zapata E, Sendra E, Sayas E, Navarro C, et al. (2011) Resistant starch as prebiotic: A review. Starch/Starke 63: 406-415.

17. Leszczynski W (2004) Resistant Starch - classification, structure, production. Polish J Food Nutr Sci 13: 37-50.

18. Nugent AP (2005) Health properties of resistant starch. Nutr Bull 30: 27-54.

19. Betty W Li (2010) Analysis of Dietary Fiber and Non digestible Carbohydrates. In: Cho SS, Finocchiaro ET (eds) Handbook of prebiotics and probiotics ingredients, CRC Press Taylor \& Francis Group, Boca Raton, pp. 1-12.

20. Mermelstein NH (2009) Analyzing for resistant starch. Food Technol 4: 80-84.

21. Jochym K, Kapusniak J, Barczynska R, Sliżewska K (2012) New starch preparations resistant to enzymatic digestion. J Sci Food Agric 92: 886-891.

22. Ouwehand A, Vesterlund S (2003) Health aspects of probiotics. IDrugs 6: 573 580.

23. Wynne AG, McCartney AL, Brostoff J, Hudspith BN, Gibson GR et al. (2004) An in vitro assessment of the effects of broad-spectrum antibiotics on the human gut microflora and concomitant isolation of a Lactobacillus plantarum with antiCandida activities. Anaerobe 10: 165-169.
24. Kapusniak J, Barczynska R, Slizewska K, Libudzisz Z (2008) Utilization of enzyme-resistant chemically modified dextrins from potato starch by Lactobacillus bacteria. Zeszyty Problemowe Postepow Nauk Rolniczych 530 445-457.

25. Lee SC, Prosky L, de Vries JW (1992) Determination of total, soluble and insoluble dietary fiber in food - enzymatic-gravimetric method, MES-TRIS buffer: collaborative study. J Assoc Off Analyt Chem 75: 395-416.

26. Ohkuma K, Matsuda I, Katta Y, Tsuji K, Ohkuma K, et al. (2000) New method for determining total dietary fiber by liquid chromatography. J AOAC Int 83 1013-1019.

27. Englyst HN, Kingman SM, Cummings JH (1992) Classification and measurement of nutritionally important starch fractions. Eur J Clin Nutr 46 Suppl 2: S33-50.

28. Shin M, Song J, Seib P (2004) In vitro digestibility of cross-linked starches RS4. Starch/ Starke 56: 478-483.

29. Nishibata T, Tashiro K, Kanahori S, Hashizume C, Kitagawa M, et al. (2009) Comprehensive measurement of total nondigestible carbohydrates in foods by enzymatic-gravimetric method and liquid chromatography. J Agric Food Chem 57: 7659-7665

30. Bielecka M, Biedrzycka E, Majkowska A, Juskiewicz J (2002) Effect of nondigestible oligosaccharides on gut micro ecosystem in rats. Food Res Inter 35: 139-144.

31. Dale JW, Park SF (2010) In: Molecular genetics of bacteria, Wiley-Blackwell, Chichester.

32. Olano-Martin E, Gibson GR, Rastell RA (2002) Comparison of the in vitro bifidogenic properties of pectins and pectic-oligosaccharides. J Appl Microbio 93: 505-511.

33. Kordyl M (2010) Ability of intestinal microorganisms to metabolize prebiotic preparations, Ph D Thesis, Technical University of Lodz, Poland, Polish.

34. Crittenden RG, Playne MJ (2009) Handbook of probiotics and prebiotics, In: Lee YK, Salminen S (edn) John Wiley \& Sons, New Jersey, pp 535-584.

35. Roberfroid MB (2007) Inulin-type fructans: functional food ingredients. J Nutr 137: 2493S-2502S

36. Swennen K, Courtin CM, Delcour JA (2006) Non-digestible oligosaccharides with prebiotic properties. Crit Rev Food Sci Nutr 46: 459-471. 